Article

\title{
Preparation and Application of Phosphorylated Xylan as a Flocculant for Cationic Ethyl Violet Dye
}

\author{
Zhongming Liu ${ }^{1}$, Dingding Xu ${ }^{1}$, Nannan Xia ${ }^{1}$, Xin Zhao ${ }^{1}$ (D), Fangong Kong ${ }^{1, *}$, \\ Shoujuan Wang ${ }^{1, *}$ and Pedram Fatehi ${ }^{2}$ \\ 1 Key Laboratory of Pulp \& Paper Science and Technology Ministry of Education, Qilu University of \\ Technology (Shandong Academy of Sciences), Jinan 250353, China; liuzhongming126@126.com (Z.L.); \\ 18364195258@163.com (D.X.); xianan00001@126.com (N.X.); zhaoxin_zixi@126.com (X.Z.) \\ 2 Department of Chemical Engineering, Lakehead University, Thunder Bay, ON P7B 5E1, Canada; \\ pfatehi@lakeheadu.ca \\ * Correspondence: kfgwsj1566@163.com (F.K.); nancy5921@163.com (S.W.); Tel.: +86-531-8963-1988 (F.K.)
}

Received: 10 February 2018; Accepted: 12 March 2018; Published: 14 March 2018

\begin{abstract}
In this study, phosphorylated birchwood xylan was produced under alkali conditions using trisodium trimetaphosphate. Three single-factor experiments were used to explore the influences of time, temperature, and the molar ratio of trisodium trimetaphosphate to xylan on the degree of substitution (DS) and charge density of xylan. The response surface methodology was used to explore the interaction of these three factors. Phosphorylated xylan with a maximum DS of 0.79 and a charge density of $-3.40 \mathrm{mmol} / \mathrm{g}$ was produced under the optimal conditions of $80^{\circ} \mathrm{C}, 4 \mathrm{~h}$, and a molar ratio of xylan/sodium trimetaphosphate (STMP) of 1/3. Fourier transform infrared (FTIR), ascorbic acid method analyses, and inductively coupled plasma-atomic emission spectrometer (ICP-AES) analyses confirmed that the phosphate groups were successfully attached to xylan. Thermogravimetric analysis confirmed that phosphorylated xylan was less stable than birchwood xylan. Furthermore, the phosphorylated xylan was applied as a flocculant for removing ethyl violet dye from a simulated dye solution. The results indicated that more than $95 \%$ of the dye was removed from the solution. The theoretical and experimental values of charge neutralization for the dye removal were close to one another, confirming that charge neutralization was the main mechanism for the interaction of dye and phosphorylated xylan. The impacts of salts on the flocculation efficiency of phosphorylated xylan were also analyzed.
\end{abstract}

Keywords: xylan; phosphorylated xylan; dye removal; flocculation

\section{Introduction}

Xylan is an abundant natural polymer with a structure similar to that of cellulose; it accounts for $15-30 \%$ of the biomass [1,2]. The polymeric backbone of xylan is composed of repeating xylose units that are connected by a $\beta-1-4$ linkage [3]. Functional groups attached to xylan can assist its modification, which helps with the application of modified xylan as a value-added product such as medicines $[4,5]$, biomaterials [6], hydrocolloids [7], micro-particles [8], and adsorbents for wastewater [9]. A cationic xylan copolymer has also been claimed to be effective as a flocculant for removing dyes from wastewater in the textile industry [10].

Ethyl violet (EV) is a triphenylmethane dye with extensive industrial applications [11]. It has been reported that a significant amount of the dye could be lost during the dyeing processes of the textile industry and thus released to the wastewater [11]. Therefore, the removal of the dye from wastewater is crucial for improving the environmental impact of the textile industry. Several chemical and physical methods have been developed to remove synthetic dyes from wastewater such as incineration, ozonation, adsorption, coagulation, electrochemical oxidation, and using membranes [12]. 
Despite a high efficiency in dye removal, the complexity and costs of the recycling for adsorbents in adsorption processes may be prohibitive to some applications. Phosphorylation has been one of the most effective chemical-modification techniques for introducing phosphate groups to polymers that have -OH functional groups to produce, for instance, adsorption materials $[13,14]$ and hydrogels $[15]$.

Among the modification methods, phosphorylation modification methods can be used to significantly enhance bioactivities [16], which comprise good antitumor, antioxidant, and antiviral activities [17]. In one study, a phosphorylated Codonopsis pilosula polysaccharide was synthesized and characterized, and its ability to inhibit the virulence of duck hepatitis A virus was compared with that of an unmodified Codonopsis pilosula polysaccharide [17]. In another study, a phosphorylated sago starch-extraction residue was prepared for the removal of cadmium from wastewater [14]. Song and coworkers produced a phosphorylated pumpkin polysaccharide with antioxidant activities [18]. Ghimici and Suflet were successful in producing phosphorylated polysaccharide derivatives as efficient separation agents for zinc and ferric-oxide particles from water [19]. Ming and Wang produced the phosphorylated Chrysanthemum indicum polysaccharide with a degree of substitution (DS) of 3.17 using the STMP-STPP (sodium trimetaphosphate, sodium tripolyphosphate) method [20]. However, the preparation of phosphorylated xylan and its application as a flocculant for removing dyes from solutions have not been reported and is, in fact, the objective of this work.

The current study investigated the production of phosphorylated xylan with STMP and the interaction of reaction parameters to obtain phosphorylated xylan with a high DS and charge density under alkali conditions. Furthermore, the characteristics of the prepared phosphorylated xylan and the application of phosphorylated xylan as a flocculant for the removal of ethyl violet dye from a simulated dye solution were analyzed. The main novelties of this work are the following: (1) the production of phosphorylated xylan and the optimization of the phosphorylation reaction of xylan by grafting STMP onto a xylan backbone; and (2) the assessment of the performance of phosphorylated xylan as a flocculant in isolating cationic dye segments from a simulated ethyl violet dye solution.

\section{Materials and Methods}

\subsection{Materials}

Xylan from birchwood, STMP used as received without further purification, and polydially ldimethylammonium chloride (PDADMAC) diluted to $0.001 \mathrm{M}$ prior to use were purchased from Sigma-Aldrich, Shanghai, China. EV dye was also obtained from Sigma Aldrich and diluted to $100 \mathrm{mg} / \mathrm{L}$ for use. All other chemicals used herein were of analytical grade and without further purification. The chemical structure of ethyl violet is presented in Figure 1. It is clear that the quaternary ammonium group contributes to the cationic charge of the dye. The cationic charge of the dye reduces to one mol per dye segment at a high $\mathrm{pH}$ due to the interaction of the hydroxyl group with the quaternary ammonium group and the deprotonation of the ternary ammonium group of the dye. At a very low $\mathrm{pH}$, the dye segment may have up to 3 moles of charged group on its segment in 1 mole dye.

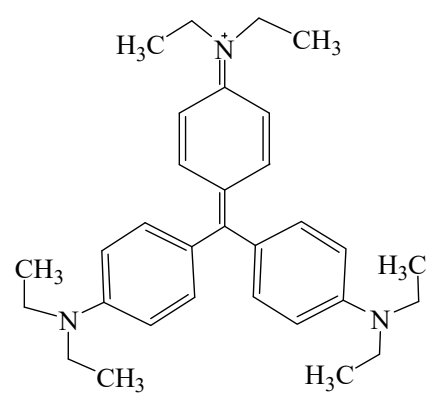

Figure 1. The chemical structure of cationic ethyl violet dye. 


\subsection{Phosphorylation of Xylan}

The phosphorylation procedure of xylan was carried out using STMP as a crosslinker, according to the method stated earlier [15,21]. Birch xylan $(1.32 \mathrm{~g}, 10 \mathrm{mmol})$ was mixed with $45 \mathrm{~mL}$ of deionized water in a closed container, STMP (10 mmol, $20 \mathrm{mmol}, 30 \mathrm{mmol}, 40 \mathrm{mmol}$, and $50 \mathrm{mmol}$ ) as a crosslinking reagent was added into the solution, $1 \mathrm{~mol} / \mathrm{L}$ sodium hydroxide was used to adjust the $\mathrm{pH}$ to 9 under constant stirring $(150 \mathrm{rpm})$, and the reaction occurred at a certain temperature $\left(50^{\circ} \mathrm{C}, 60^{\circ} \mathrm{C}, 70^{\circ} \mathrm{C}, 80^{\circ} \mathrm{C}\right.$ and $90^{\circ} \mathrm{C}$ ) for $2,3,4,5$, or $6 \mathrm{~h}$. Upon completion, the solution was cooled to room temperature and neutralized with a $1 \mathrm{~mol} / \mathrm{L}$ hydrochloric acid solution. Next, the solution was dropped into $200 \mathrm{~mL}$ of $95 \%$ ethanol solution. The precipitate was then washed twice with $200 \mathrm{~mL}$ of $95 \%$ ethanol and dialyzed with the membrane dialysis for $24 \mathrm{~h}$ against deionized water. Finally, the dialyzed samples were dried in a blast oven to obtain purified phosphorylated xylan. In this set of experiments, the reaction was carried out at one variable parameter while the other condition was fixed, one-factor experiments. The DS and charge density of the phosphorylated xylan was used as the response of molar ratio of xylan to STMP, reaction time, and temperature to the reaction. All the experiments were repeated three times, and the average values reported in this work.

The reaction mechanism of xylan with STMP (as a crosslinking agent) involved in this study was a reaction between the hydroxyl groups in the xylan and metaphosphate groups in STMP, leading to phosphate ester (O-P-O) linkages between two polysaccharide moieties to produce phosphorylated xylan [21-23], as shown in Figure 2.

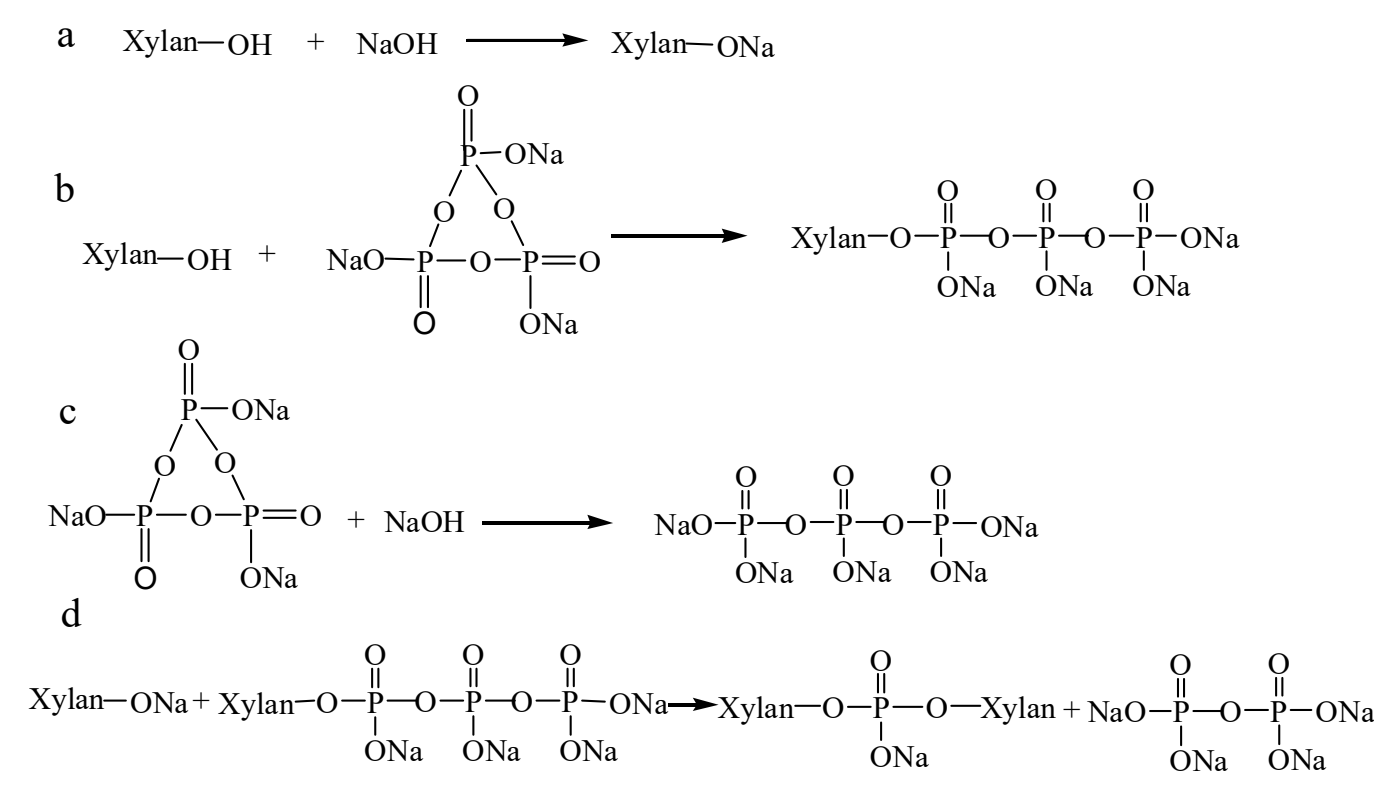

Figure 2. The reaction of xylan and sodium trimetaphosphate (STMP).

\subsection{Experimental Design}

Response surface methodology (RSM) is a powerful technique that can be applied to explore the interactions between factors in experiments and to optimize the operating conditions to obtain the best results [24]. To explore the interaction of reaction time, temperature, and the ratio of xylan/STMP in the xylan phosphorylation, Design-Expert Version 8.0.5 software (State-Ease, MN, USA) was used. In this set of experiments, three factors and three levels were considered in 17 runs according to the Box-Behnken method. The factors and levels are listed in Table 1. The DS and charge density of phosphorylated xylan were used as responses of the factors to the reaction. Five replicated experiments were used to evaluate and reduce measurement errors. The experiments were repeated three times, and the average values reported in this work. 
Table 1. The parameters and outcomes of phosphorylation of xylan.

\begin{tabular}{ccccccc}
\hline Run & $\begin{array}{c}\text { Xylan/STMP, } \\
\text { mol/mol }\end{array}$ & Temperature, ${ }^{\circ} \mathbf{C}$ & Time, $\mathbf{h}$ & $\begin{array}{c}\text { Phosphorus } \\
\text { Content, } \%\end{array}$ & DS & $\begin{array}{c}\text { Charge Density, } \\
\text { mmol/g }\end{array}$ \\
\hline 1 & $1 / 3$ & 70.00 & 4.00 & 10.41 & 0.76 & 3.30 \\
2 & $1 / 3$ & 70.00 & 4.00 & 10.41 & 0.76 & 3.30 \\
3 & $1 / 3$ & 70.00 & 4.00 & 10.41 & 0.76 & 3.30 \\
4 & $1 / 5$ & 70.00 & 2.00 & 2.53 & 0.12 & 0.92 \\
5 & $1 / 3$ & 70.00 & 4.00 & 10.41 & 0.76 & 3.30 \\
6 & $1 / 1$ & 50.00 & 4.00 & 5.21 & 0.28 & 1.62 \\
7 & $1 / 3$ & 50.00 & 6.00 & 5.64 & 0.31 & 1.81 \\
8 & $1 / 5$ & 90.00 & 4.00 & 8.82 & 0.58 & 2.85 \\
9 & $1 / 3$ & 90.00 & 2.00 & 1.75 & 0.08 & 0.65 \\
10 & $1 / 3$ & 70.00 & 4.00 & 10.41 & 0.76 & 3.30 \\
11 & $1 / 1$ & 90.00 & 4.00 & 5.06 & 0.27 & 1.62 \\
12 & $1 / 5$ & 70.00 & 6.00 & 8.41 & 0.54 & 2.76 \\
13 & $1 / 3$ & 90.00 & 6.00 & 8.10 & 0.51 & 2.64 \\
14 & $1 / 1$ & 70.00 & 2.00 & 1.33 & 0.06 & 0.49 \\
15 & $1 / 1$ & 70.00 & 6.00 & 4.44 & 0.23 & 1.45 \\
16 & $1 / 5$ & 50.00 & 4.00 & 6.19 & 0.35 & 1.97 \\
17 & $1 / 3$ & 50.00 & 2.00 & 0.91 & 0.04 & 0.32 \\
\hline
\end{tabular}

\subsection{Analytical Methods}

\subsubsection{Fourier Transform Infrared (FTIR) Analysis}

FTIR analysis was conducted on the xylan and phosphorylated xylan samples using a FTIR spectrophotometer (Bruker VERTEX70, Rheinstetten, Germany). In this measurement, unmodified and phosphorylated xylan samples of $0.01 \mathrm{~g}$ each were used. Each spectrum was recorded with 32 scans in transmittance mode with a resolution of $0.5 \mathrm{~cm}^{-1}$ within the range 400 to $4000 \mathrm{~cm}^{-1}$.

\subsubsection{Charge Density Analysis}

Approximately unmodified and phosphorylated xylan samples of $0.02 \mathrm{~g}$ each were dissolved in $100 \mathrm{~mL}$ of deionized water and ultrasounded at $30^{\circ} \mathrm{C}$ for $1 \mathrm{~h}$. The solution was used to measure charge density using a particle-charge detector (Mutek, PCD 03, Herrsching, Germany) against a $0.001 \mathrm{M}$ PDADMAC standard solution.

\subsubsection{Determination of Phosphorus Content and Degree of Substitution (DS)}

The phosphate radical content of the phosphorylated xylan was determined using the ascorbic-acid method [20]. According to the established formula deduced from the expression for the phosphorus content ratio, Equations (1) and (2) for calculating DS can be obtained as follows.

$$
\begin{gathered}
P \%=\frac{D S \times 3 b \times 100}{(a+D S \times c)} \\
\text { DS }=\frac{a \times P \%}{300 b-c \times P \%}=\frac{132 \times P \%}{300 \times 31-124 \times P \%}=\frac{1.32 \times P \%}{93-1.24 \times P \%}
\end{gathered}
$$

where $P \%$ represents the phosphorus content; $a$ is the molecular weights of the unmodified xylan's monomeric unit, $132 \mathrm{~g} / \mathrm{mol} ; b$ is the mass of phosphorous atom, $31 \mathrm{~g} / \mathrm{mol}$; and $c$ is the added molecular weight when $-\mathrm{OH}$ in xylan was substituted by $-\mathrm{OPO}_{3} \mathrm{Na}_{2}[25], 124 \mathrm{~g} / \mathrm{mol}$.

\subsubsection{Molecular Weight Analysis}

Dried unmodified and phosphorylated xylan samples of approximately $5 \mathrm{mg}$ each were dissolved in $0.1 \mathrm{~mol} / \mathrm{L} \mathrm{NaNO}_{3}$ by stirring at $500 \mathrm{rpm}$ for $36 \mathrm{~h}$ at $35^{\circ} \mathrm{C}$, and the solutions were then filtered using 
a $0.2 \mu \mathrm{m}$ nylon filter. The filtered solutions were used for molecular weight analysis. The molecular weight analysis of the samples was carried out using gel permeation chromatography, Heleos-II GPC (Wyatt Technology, Santa Barbara, CA, USA) with a multi-angle laser light scattering detector. The columns of PolyAnalytic PAA 206 and PAA 203 were set up at $35^{\circ} \mathrm{C}$, and a $0.1 \mathrm{~mol} / \mathrm{L} \mathrm{NaNO}_{3}$ solution was used as a solvent and an eluent. The flow rate was set at $0.50 \mathrm{~mL} / \mathrm{min}$, while poly(ethylene oxide)s were used as standard samples for the calibration of this aqueous system. The degree of polymerization of unmodified and modified xylan was calculated based on Equation (3).

$$
\text { Degree of polymerization }=\frac{M_{n}}{132+D S \times 124}
$$

where $M_{n}$ is the number averaged molecular weight of xylan, $\mathrm{g} / \mathrm{mol}$. The molecular weight of xylan's monomeric unit is $132 \mathrm{~g} / \mathrm{mol}$. DS is the degree of substitution of modified xylan. The added molecular weight when $-\mathrm{OH}$ in xylan was substituted by $-\mathrm{OPO}_{3} \mathrm{Na}_{2}$ is $124 \mathrm{~g} / \mathrm{mol}$.

\subsubsection{Elemental Analysis}

Elemental analysis of phosphorus in xylan and phosphorylated xylan was carried out using an inductively coupled plasma-atomic emission spectrometer (ICP-AES; ICAP 9000, Shimadzu, Tokyo, Japan). The sample was dissolved in $0.1 \mathrm{~mol} / \mathrm{L} \mathrm{HCl}$ and further diluted with water. The measured concentration of phosphorus in aqueous solution was converted into actual phosphorus content, taking into consideration the dilution factor [26]. The contents of carbon (C), hydrogen (H), and oxygen $(\mathrm{O})$ in the xylan and phosphorylated xylan were measured with an elemental analyzer (Vario EL III, Elementar Analysensysteme, Hanau, Germany). The samples were combusted at up to $900{ }^{\circ} \mathrm{C}$ to $1200^{\circ} \mathrm{C}$ for analytical accuracy with a large dynamic range of elemental concentration, e.g., up to $30 \mathrm{mg}$ of carbon absolute.

\subsubsection{Thermogravimetric Analysis}

The thermal analysis of unmodified and phosphorylated xylan samples was performed on a thermogravimetric analyzer (TGA Q50, New Castle, DE, USA). Samples of 3-10 mg were heated from room temperature to $600{ }^{\circ} \mathrm{C}$ at the rate of $10{ }^{\circ} \mathrm{C} / \mathrm{min}$ under a nitrogen environment to examine the thermal stability properties.

\subsubsection{Viscosity Measurement}

The viscosities of xylan and phosphorylated xylan were measured at different concentrations at $25^{\circ} \mathrm{C}$ using a Brookfield DV-II + Pro viscometer (Brookfield Engineering Laboratory, Inc., Middlesboro, MA, USA). The viscosities were measured in aqueous solutions ( $\mathrm{pH} 7$ ) at room temperature. In this set of experiments, different concentrations of xylan or phosphorylated xylan solutions were placed in the spindle No. S61 of the viscometer, and the spindle rotation was adjusted from 1 up to $100 \mathrm{rpm}$ to measure the viscosity of the samples.

\subsubsection{Flocculation Analysis}

In this set of experiments, ethyl violet dye solutions were prepared at different concentrations by dissolving the dye in deionized water, and the $\mathrm{pH}$ of the dye solutions was adjusted to the desired value by adding a $\mathrm{HCl}$ or $\mathrm{NaOH}$ solution to it. Then, different amounts of phosphorylated xylan solution were added to the dye solutions, and the mixtures were continuously stirred at $30{ }^{\circ} \mathrm{C}$ for $30 \mathrm{~min}$ at $150 \mathrm{rpm}$. After that, the mixtures were centrifuged at 10,000 rpm for $10 \mathrm{~min}$, and the filtrate was collected for analysis. The concentration of the dye in the solutions (before mixing with phosphorylated xylan and after centrifugation) was measured using a UV-2550 spectrophotometer 
(Shimadzu Co, Kyoto, Japan) at a wavelength of $596 \mathrm{~nm}$. The removal of the dye from the solution was calculated according to the following equation:

$$
\text { Dye removal }=\frac{C_{0}-C}{C_{0}} \times 100 \%
$$

where $C_{0}$ refers to the concentration of the ethyl violet dye in the control sample $(\mathrm{mg} / \mathrm{L})$; and $C$ refers to the concentration of the dye after treatment with phosphorylated xylan $(\mathrm{mg} / \mathrm{L})$. To investigate the impact of salts on the efficiency of phosphorylated xylan in removing the dye from the solution, dye solutions (100 mg/L) containing $0.01 \mathrm{~mol} / \mathrm{L} \mathrm{NaCl}, \mathrm{NaNO}_{3}$, and $\mathrm{FeSO}_{4}$ were prepared. Phosphorylated xylan was added to $30 \mathrm{~mL}$ of a dye solution containing salts at $\mathrm{pH} 9$. After that, the dye solution was treated as stated above (the mixtures were centrifuged at 10,000 rpm for $10 \mathrm{~min}$, and the filtrate was collected for analysis), and the removal of the dye was determined according to Equation (4). The experiments were repeated three times, and the average values reported in this work.

\subsubsection{COD Analysis}

The chemical oxygen demand (COD) test is commonly used to indirectly measure the amount of organic pollutants found in wastewater. In this set of experiments, the samples were treated with potassium dichromate under acidic conditions with silver as a catalyst at $150{ }^{\circ} \mathrm{C}$ for $2 \mathrm{~h}$ in a thermoreactor (CR 2200, WTW GmbH, Weilheim, Germany). The solutions were cooled for $20 \mathrm{~min}$ in the digester then stored in the dark for $30 \mathrm{~min}$ [27]. The concentration of the COD in the solutions (before and after mixing with phosphorylated xylan) was measured using the UV-2550 spectrophotometer at the wavelength of $620 \mathrm{~nm}$. The COD removal was calculated according to Equation (5):

$$
\text { COD removal }=\frac{C_{\mathrm{o}}-C}{C_{\mathrm{o}}} \times 100 \%
$$

where $C_{\mathrm{o}}$ and $C$ are the COD concentrations of the dye solutions before and after treating with phosphorylated xylan, $\mathrm{mg} / \mathrm{L}$, respectively.

\section{Results}

\subsection{Influences of Reaction Conditions on DS and Charge Density of Phosphorylated Xylan}

\subsubsection{Molar Ratio of Xylan/STMP}

Figure 3 illustrates the impact of the xylan/STMP ratio on the DS and charge density of phosphorylated xylan. The DS and charge density increased when the molar ratio was increased from $1 / 1$ to $1 / 3$, and a higher than molar ratio of $1 / 3$ insignificantly changed the DS and charge density. The results confirmed that the increase in the concentration of STMP enhanced the DS and charge density of the produced phosphorylated xylan; this may be due to the increase in the collision chances of chemical agents at higher concentrations in the reaction media. It was also noted that the highest molar ratio of $1 / 5$ did not improve the properties of phosphorylated xylan; this may be attributed to the progress in side reactions (Figure 2c). This phenomenon has also been claimed in the past in the preparation of Pullulan-STMP hydrogels [23]. Therefore, the molar ratio of 1/3 for xylan/STMP was selected for further analysis. 


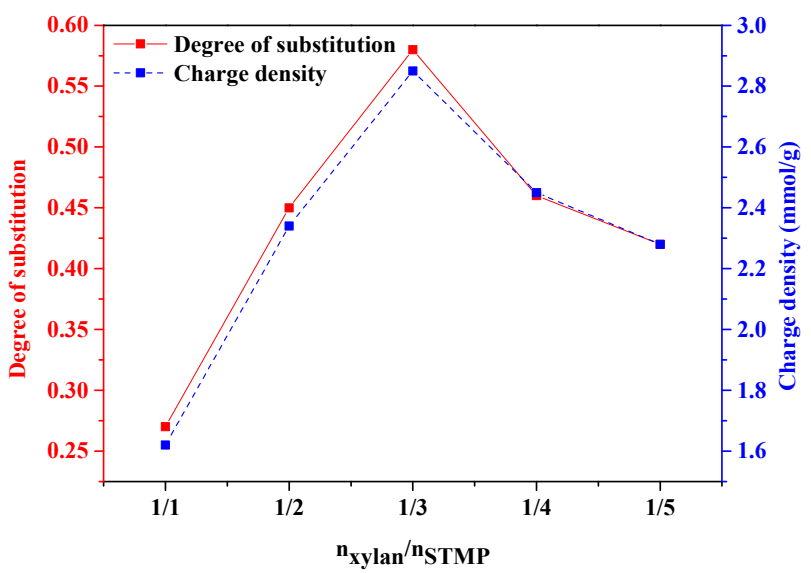

Figure 3. The effect of molar ratio of xylan/STMP $\left(n_{\text {xylan }} / n_{\text {STMP }}\right)$ on the degree of substitution and charge density of phosphorylated xylan (conducted at $80^{\circ} \mathrm{C}$ for $3 \mathrm{~h}$ ).

\subsubsection{Temperature}

The effect of the reaction temperature on the DS and charge density of phosphorylated xylan is illustrated in Figure 4. It is evident that, with the increase in the reaction temperature from $50{ }^{\circ} \mathrm{C}$ to $80^{\circ} \mathrm{C}$, the DS and charge density of phosphorylated xylan increased to 0.58 and $-2.85 \mathrm{mmol} / \mathrm{g}$, respectively, due to favorable conditions for phosphorylation. However, further temperature increases to $90{ }^{\circ} \mathrm{C}$ slightly reduced the DS and the charge density of phosphorylated xylan to 0.63 and $-2.64 \mathrm{mmol} / \mathrm{g}$, respectively. The decrease in the DS and charge density at a temperature higher than $80{ }^{\circ} \mathrm{C}$ was due to the degradation of xylan and the generation of undesired products as stated in previous research [24].

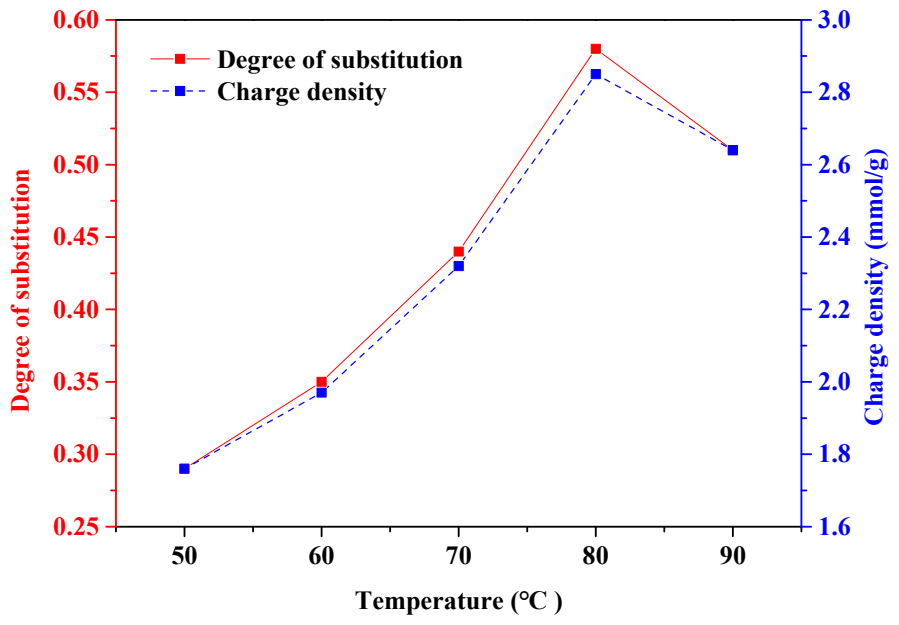

Figure 4. The effect of temperature on the degree of substitution and charge density of phosphorylated xylan (conducted at the xylan/STMP molar ratio of $1 / 3$ for $3 \mathrm{~h}$ ).

\subsubsection{Time}

Figure 5 represents the influence of reaction time on the DS and charge density of phosphorylated xylan. The maximum DS of 0.79 and charge density of $-3.40 \mathrm{mmol} / \mathrm{g}$ were obtained at $4 \mathrm{~h}$. There was an increase in the DS and charge density of phosphorylated xylan when time was increased from $2 \mathrm{~h}$ to $4 \mathrm{~h}$, after which they decreased. However, when the time was longer than $4 \mathrm{~h}$, the DS and charge density of phosphorylated xylan decreased due to the increase of the undesired product (sodium tripolyphosphate and pyrophosphate) hindering the production of phosphorylated xylan [24]. 


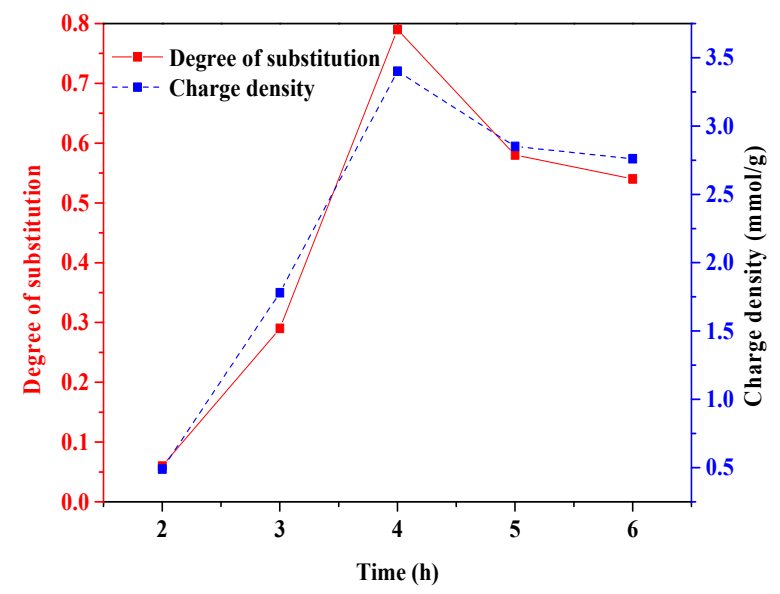

Figure 5. The effect of time on the degree of substitution and charge density of phosphorylated xylan (conducted at the xylan/STMP molar ratio of $1 / 3$ and $80^{\circ} \mathrm{C}$ ).

\subsection{Analysis of Variance (ANOVA)}

The results in Figures 3-5 do not show which reaction parameters had the most significant impact on the charge density and DS of the phosphorylated xylan. The relationship between the experimental factors and the generated results as well as the contribution of experimental factors can be determined by the ANOVA statistical technique. To further understand the impact of process parameters on the efficiency of reaction and to be able to predict the phosphorylation reaction of xylan, the outcomes of the modeling analysis in Table 1 (i.e., sum of squares, degrees of freedom, mean square, $F$-value, and $p$-values) were estimated and are presented in Table 2 . In the case of $p$-value, $\mathrm{A}, \mathrm{B}, \mathrm{C}, \mathrm{AB}, \mathrm{AC}$, $\mathrm{BC}, \mathrm{A}^{2}, \mathrm{~B}^{2}$, and $\mathrm{C}^{2}$ were less than 0.05 , implying that the correlation factors were significant [28]. The predicted $\mathrm{R}^{2}$ of 0.9790 and 0.9395 for DS and charge density were in agreement with the adjusted $\mathrm{R}^{2}$ of 0.9970 and 0.9914 , respectively. In this case, the F-value of B (Temperature) was the smallest of the three factors, indicating the negligible effect of temperature when compared to other factors (time and xylan/STMP molar ratio) in increasing the DS and charge density of phosphorylated xylan. Furthermore, it was clear that time had a major effect on the DS and charge density of phosphorylated xylan [24].

Table 2. ANOVA analysis for degree of substitute (DS) and charge density of phosphorylated xylan.

\begin{tabular}{ccccccccc}
\hline & \multicolumn{2}{c}{ Sum of Squares } & \multicolumn{2}{c}{ Mean Square } & \multicolumn{2}{c}{ F-Value } & \multicolumn{2}{c}{$p$-Value } \\
\cline { 2 - 8 } Source & DS & $\begin{array}{c}\text { Charge Density, } \\
\text { mmol/g }\end{array}$ & DS & $\begin{array}{c}\text { Charge Density, } \\
\text { mmol/g }\end{array}$ & DS & $\begin{array}{c}\text { Charge Density, } \\
\text { mmol/g }\end{array}$ & $\begin{array}{c}\text { DS } \\
\text { Charge Density, } \\
\text { mmol/g }\end{array}$ \\
\hline Model & 1.20 & 18.66 & 0.13 & 2.07 & 592.23 & 204.97 & 0.0001 & 0.0001 \\
xylan/STMP (A) & 0.070 & 1.38 & 0.070 & 1.38 & 312.50 & 136.22 & 0.0001 & 0.0001 \\
Temperature (B) & 0.026 & 0.52 & 0.026 & 0.52 & 117.56 & 51.43 & 0.0001 & 0.0002 \\
Time (C) & 0.21 & 4.93 & 0.21 & 4.93 & 924.50 & 487.41 & 0.0001 & 0.0001 \\
AB & 0.014 & 0.19 & 0.014 & 0.19 & 64.00 & 19.14 & 0.0001 & 0.0033 \\
AC & 0.016 & 0.19 & 0.016 & 0.19 & 69.44 & 19.14 & 0.0001 & 0.0033 \\
BC & 0.006 & 0.063 & 0.006 & 0.063 & 28.44 & 6.18 & 0.0011 & 0.0419 \\
A & 0.16 & 1.61 & 0.16 & 1.61 & 702.49 & 158.74 & 0.0001 & 0.0001 \\
B & 0.16 & 1.88 & 0.16 & 1.88 & 720.73 & 185.48 & 0.0001 & 0.0001 \\
C $^{2}$ & 0.46 & 6.87 & 0.46 & 6.87 & 2022.49 & 679.40 & 0.0001 & 0.0001 \\
\hline
\end{tabular}

\subsection{Properties of Phosphorylated Xylan with the Maximum DS and Charge Density}

The properties of phosphorylated xylan with a DS of 0.79 and charge density of $-3.40 \mathrm{mmol} / \mathrm{g}$, which were produced under the conditions of $80^{\circ} \mathrm{C}, 4 \mathrm{~h}$, and with a xylan/STMP molar ratio of $1 / 3$, are listed in Table 3. The weight-average molecular weight $(M w)$ and number-average molecular weight $(\mathrm{Mn})$ of the phosphorylated xylan sample were $23,500 \mathrm{~g} / \mathrm{mol}$ and 18,600 $\mathrm{g} / \mathrm{mol}$, respectively, whereas those of unmodified xylan were $20,800 \mathrm{~g} / \mathrm{mol}$ and $11,850 \mathrm{~g} / \mathrm{mol}$, respectively. A slight increase 
in the molecular weight of xylan due to the grafting phosphate group was also observed in another work [29]. The decrease in the polydispersity, the ratio of $M w$ to $M n$, may be due to the grafting of the phosphate group to xylan. The degree of polymerization of xylan was decreased from 90 to 81 , which was probably due to the degradation of the xylan chain in alkaline conditions [30].

Table 3. The properties of unmodified xylan and phosphorylated xylan.

\begin{tabular}{cccccc}
\hline Samples & $\begin{array}{c}\text { Charge Density } \\
(\mathbf{m m o l} / \mathbf{g})\end{array}$ & $\boldsymbol{M w} \mathbf{( g / \mathbf { m o l } )}$ & $\boldsymbol{M n} \mathbf{( g / m o l )}$ & $\boldsymbol{M w} / \mathbf{M n}$ & $\begin{array}{c}\text { Degree of } \\
\text { Polymerization }\end{array}$ \\
\hline Unmodified Xylan & -0.12 & 20,800 & 11,850 & 1.76 & 90 \\
Phosphorylated Xylan & -3.40 & 23,500 & 18,600 & 1.26 & 81 \\
\hline
\end{tabular}

\subsection{Elemental Analysis}

Elemental analysis of the xylan and phosphorylated xylan was carried out to determine the content of carbon, hydrogen, oxygen, and phosphorous in xylan and phosphorylated xylan and the data is listed in Table 4 . The $C_{5}$ unit formulas of xylan and phosphorylated xylan were also calculated based on the elemental analysis. It was clear that the carbon content decreased from 42.5 to $19.1 \%$, the oxygen content increased from 47.1 to $55.9 \%$, and the hydrogen content decreased from 5.8 to $2.21 \%$, which was attributed to the high content of oxygen and the low content of carbon and no hydrogen in $-\mathrm{OPO}_{3} \mathrm{Na}_{2}$ grafted to xylan backbone. The content of phosphorus increased from $0.03 \%$ of unmodified xylan to $23.10 \%$ of phosphorylated xylan. The phosphorus here was clearly from the $-\mathrm{OPO}_{3} \mathrm{Na}_{2}$ segment in phosphorylated xylan as the unmodified xylan only had unnoticeable phosphorus content $(0.03 \mathrm{wt} \%)$. These changes confirmed the successful phosphorylation of xylan using STMP. In addition, the phosphorous content measured using ICP-AES, 31.81\%, was used to calculate the DS through Equation (1), and was 0.783 , which was very close to the 0.79 value obtained using the ascorbic-acid method.

Table 4. The elemental analysis of xylan and phosphorylated xylan.

\begin{tabular}{cccccc}
\hline Samples & $\mathbf{P}$, wt \% & $\mathbf{C , w t} \%$ & $\mathbf{H}$, wt \% & O, wt \% & Formula \\
\hline Xylan & 0.03 & 42.50 & 5.80 & 47.10 & $\mathrm{C}_{5} \mathrm{H}_{8.22} \mathrm{O}_{4.13} \mathrm{P}_{0.001}$ \\
Phosphorylated xylan & 31.81 & 26.22 & 3.15 & 70.90 & $\mathrm{C}_{5} \mathrm{H}_{7.21} \mathrm{O}_{10.13} \mathrm{P}_{2.34}$ \\
\hline
\end{tabular}

\subsection{FTIR Analysis}

FTIR spectra of unmodified and phosphorylated xylan are illustrated in Figure 6. The absorption peaks at 3427, 2928, 1648, 1465, 1250,1164,1042, 985, and $895 \mathrm{~cm}^{-1}$ were associated with xylan. A broad absorbance peak at $3427 \mathrm{~cm}^{-1}$ corresponded to the hydroxyl stretching vibration [31]. The absorption peak at $2928 \mathrm{~cm}^{-1}$ was assigned to the symmetric $\mathrm{C}-\mathrm{H}$ stretching vibration, and that at $1648 \mathrm{~cm}^{-1}$ contributed to the absorbed water in the samples [32]. The strong peak at $1042 \mathrm{~cm}^{-1}$ was assigned to $\mathrm{C}-\mathrm{O}$ stretching in $\mathrm{C}-\mathrm{O}-\mathrm{C}$ linkages [33,34]. The sharp peak at $895 \mathrm{~cm}^{-1}$ was assigned to the $\beta$-glucosidic linkage between the xylose units, indicating that the xylose residues were linked by $\beta$-form bonds [35]. The low intensity of the bands at $985 \mathrm{~cm}^{-1}$ and $1164 \mathrm{~cm}^{-1}$ suggested the presence of arabinosyl units, which were only attached at position 3 of the xylopyranosyl constituents [35]. The region between $1465 \mathrm{~cm}^{-1}$ and $1042 \mathrm{~cm}^{-1}$ related to the $\mathrm{C}-\mathrm{H}$ and $\mathrm{C}-\mathrm{O}$ bond stretching frequencies. Compared with the spectrum of xylan, the spectrum of phosphorylated xylan appeared to have three new peaks at $1293 \mathrm{~cm}^{-1}, 1105 \mathrm{~cm}^{-1}$, and $995 \mathrm{~cm}^{-1}$, respectively. The new adsorption peak at $1293 \mathrm{~cm}^{-1}$ was ascribed to the stretching vibration of the $\mathrm{P}=\mathrm{O}$ band. The peak at $1105 \mathrm{~cm}^{-1}$ originated from the stretching vibration of the $\mathrm{C}-\mathrm{O}-\mathrm{P}$ band $[14,17]$. The peak at $995 \mathrm{~cm}^{-1}$ was ascribed to the $\mathrm{O}-\mathrm{P}-\mathrm{O}$ band [36]. These new peaks confirmed that the phosphorylated xylan was successfully synthesized. 


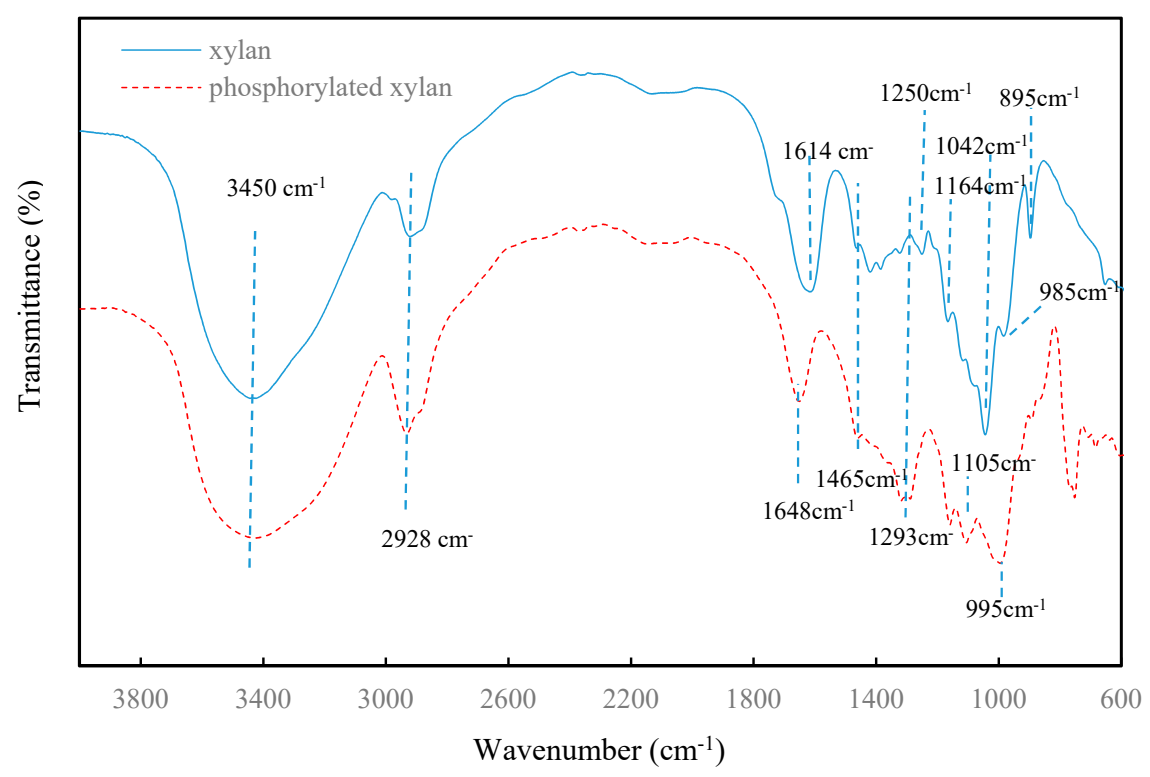

Figure 6. FTIR spectra of xylan and phosphorylated xylan.

\subsection{Thermogravimetric Analysis}

Thermal analysis of unmodified xylan and phosphorylated xylan are illustrated in Figure 7. The samples of unmodified xylan and phosphorylated xylan were analyzed at a heating rate of $10{ }^{\circ} \mathrm{C} / \mathrm{min}$ under a nitrogen environment. The weight of unmodified xylan and phosphorylated xylan decreased gradually with the increase in the temperature from room temperature to $150{ }^{\circ} \mathrm{C}$; this was attributed to the loss of moisture in the samples [37]. The weight loss of unmodified xylan started at around $230{ }^{\circ} \mathrm{C}$ while that of phosphorylated xylan started at $210{ }^{\circ} \mathrm{C}$. The main degradation temperature of xylan ranged from $250{ }^{\circ} \mathrm{C}$ to $450{ }^{\circ} \mathrm{C}$; however, that of phosphorylated xylan ranged from $240{ }^{\circ} \mathrm{C}$ to $350{ }^{\circ} \mathrm{C}$; this suggests that the chemical modification led to the lower thermal stability of the final products [27]. When the temperature reached $400{ }^{\circ} \mathrm{C}$, only $11 \mathrm{wt} \%$ of the xylan sample was left. However, at this temperature, more than $20 \mathrm{wt} \%$ of phosphorylated xylan was left, which was mainly due to the phosphorylated groups as stated in previous works [13].

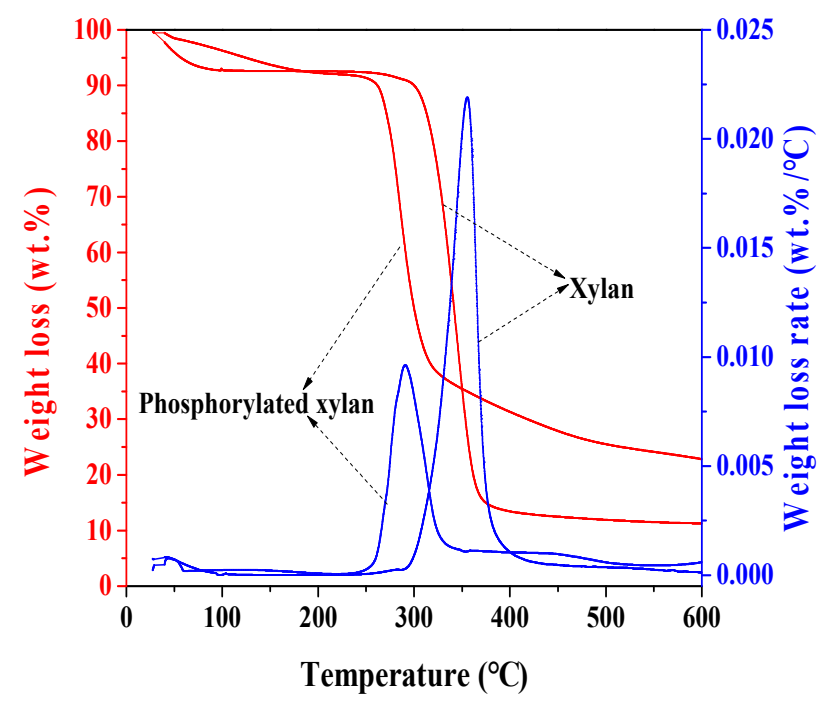

Figure 7. Weight loss and weight loss rate of xylan and phosphorylated xylan. 


\subsection{Viscosity Analysis of Xylan and Phophorylated Xylan Solutions}

Figure 8 shows the dynamic viscosity of xylan and phosphorylated xylan solutions at concentrations of $5 \%, 10 \%$, and $15 \%(w / w)$. The viscosity of xylan and phosphorylated xylan solutions decreased with increasing shear rate at the same concentration, exhibiting a pseudoplastic or shear-thinning behavior in the range of shear rates tested. Figure 8 also indicates that the viscosity of the xylan and phosphorylated xylan solutions increased when the concentration was increased. This was probably due to the stronger entanglements between xylan molecules at a higher concentration. When the shear rate increases, this network structure is destroyed; therefore, a shear thinning behavior is observed [38,39]. It was also found that the phosphorylated xylan showed a higher viscosity than unmodified xylan, which was probably due to the higher molecular weight and stronger intermolecular interactions between the phosphorylated xylan molecules.

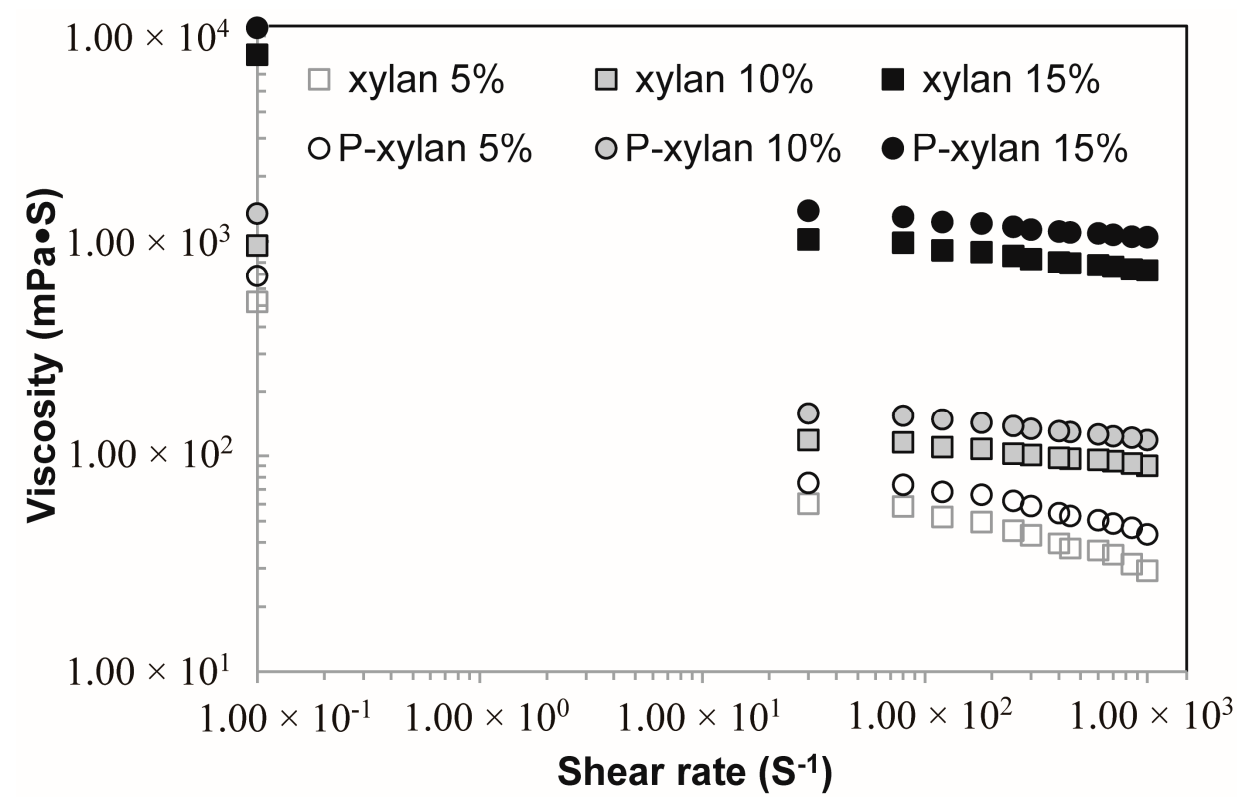

Figure 8. Viscosity of xylan and phosphorylated xylan (P-xylan) solutions as function of shear rate at various concentration.

\subsection{Flocculation Analysis}

\subsubsection{The Effect of Dye Concentrations and Phosphorylated Xylan Concentrations on Dye Removal}

The effect of dye concentration on the efficiency of phosphorylated xylan is illustrated in Figure 9A. The dye concentration was varied between 40 and $120 \mathrm{mg} / \mathrm{L}$ so that the optimum concentration of phosphorylated xylan for removing dyes with different concentrations could be determined. As expected, with an increase in the concentration of dye, the optimum phosphorylated xylan concentration for dye removal also increased. This indicated that the initial concentration of dye was an important factor in the dye's interaction with phosphorylated xylan [40].

Based on the results in Figure 9A, the correlation between the optimum concentration of phosphorylated xylan (i.e., the concentration that generated the maximum dye removal in Figure 9A) and the initial dye concentrations is illustrated in Figure 9B. Based on the charge densities of phosphorylated xylan and dye and by considering the charge neutralization mechanism, the concentration of phosphorylated xylan required for achieving the maximum dye removal can be calculated theoretically. The theoretical concentration of phosphorylated xylan needed to achieve the maximum dye removal at different dye concentrations is depicted in Figure 9B. When the concentration of dye was low, the theoretical and experimental values were close, confirming the importance of charge neutralization. When the concentration of the dye was high, the concentration required 
experimentally was much higher than that required theoretically [27]. This is because not all of the charges on dye or phosphorylated xylan are available for interaction, and this is more observable at higher dye concentrations that have stronger charge repulsion from adjacent polyelectrolytes [27,41]. The deviation seen in Figure 9B may be attributed to: (1) experimental errors; (2) unstoichiometric charge interaction of phosphorylated xylan and the dye segment; as well as (3) hydrogen bonding development between the dye and phosphorylated xylan in the solution.

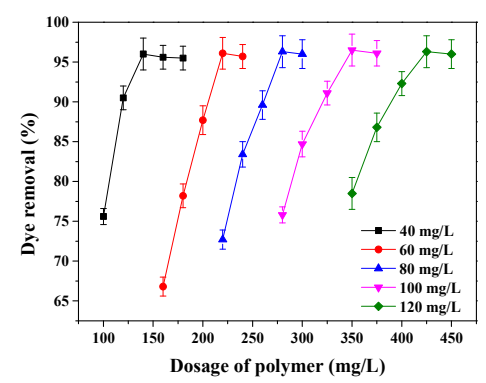

(A)

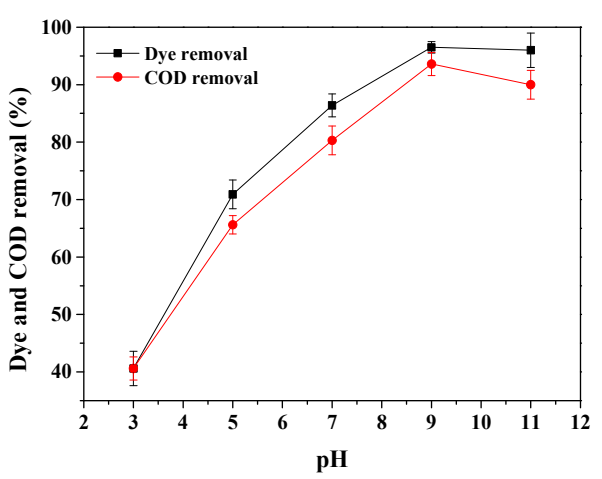

(C)

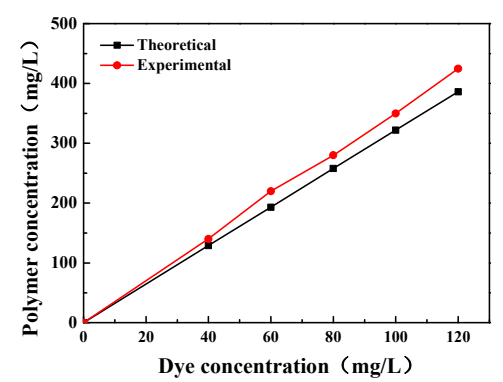

(B)

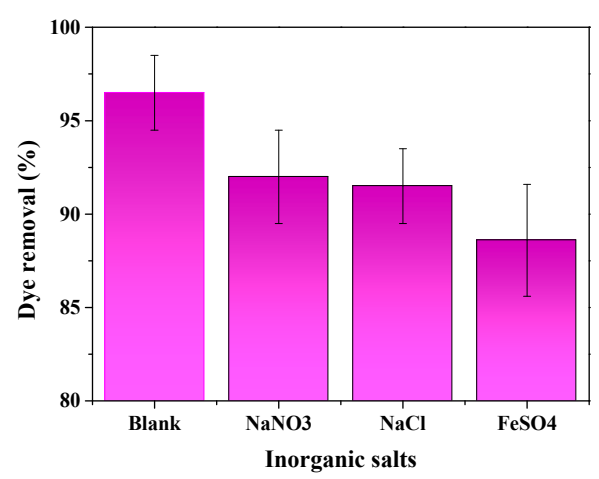

(D)

Figure 9. (A) The effect of initial dye and phosphorylated xylan concentrations on dye removal under conditions of $30^{\circ} \mathrm{C}$ and $\mathrm{pH}$ 9; (B) the relationship between optimum and theoretical phosphorylated xylan dosage and initial concentration; (C) the effect of $\mathrm{pH}$ on dye removal under conditions of $100 \mathrm{mg} / \mathrm{L}$ dye concentration, $350 \mathrm{mg} / \mathrm{L}$ phosphorylated xylan concentration and $30^{\circ} \mathrm{C}$; and (D) the effect of inorganic salts on dye removal under the conditions of $100 \mathrm{mg} / \mathrm{L}$ dye concentration, $350 \mathrm{mg} / \mathrm{L}$ phosphorylated xylan concentration, $\mathrm{pH} 9$, and $30^{\circ} \mathrm{C}$.

\subsubsection{The Effect of $\mathrm{pH}$ on Dye and COD Removal}

Figure $9 \mathrm{C}$ demonstrates the effect of $\mathrm{pH}$ on the dye and COD removals. As expected, the dye removal was almost complete under alkaline conditions, $\mathrm{pH}$ 9, and were insignificantly changed by increasing $\mathrm{pH}$ from 9 to 11 , but COD removal slightly decreased. This may indicate that phosphorylated xylan was more effectively involved in the flocculant formation with the dye segments at a $\mathrm{pH}$ higher than 9. Under an acidic $\mathrm{pH}$, free protons would interact with phosphorylated xylan, which would reduce their efficiency [42]. As stated earlier, the cationic charge density of dye is reduced at a high $\mathrm{pH}$, which hampers the dye's water solubility. The reduced charge density also implies that the minimum amount of phosphorylated xylan required for efficient dye removal based on the charge neutralization is reduced. At a high $\mathrm{pH}$ of 11, the hydroxyl group may interact with the dye segments, reducing the attractive force developed between the phosphorylated xylan and dye for flocculant formation [43]. 


\subsubsection{Inorganic Salts}

Salts are generally available in dyeing wastewater and may affect the efficiency of phosphorylated xylan in dye removals from the solution. Figure 9D illustrates the impact of various inorganic salts ( $0.01 \mathrm{~mol} / \mathrm{L}$ concentration) on dye removals using phosphorylated xylan. In general, the addition of various inorganic salts slightly reduced the efficiency of phosphorylated xylan in removing dyes from the solutions. Ferrous sulfate reduced the dye removal by $10 \%$, which was consistent with previously reported results [27]. When the monovalent $\mathrm{Na}^{+}$cation is added to the dye solution, it generates the electrolyte effect, which reduces the dye removal efficiency of phosphorylated xylan. If multivalent cations such as $\mathrm{Fe}^{2+}$ are present in the dye solution, there is competition between the cation and the dye segments to bind to the anionic sites of the phosphorylated xylan. These chelated units exert a partially positive charge, which promotes electrostatic repulsion between the phosphorylated xylan and the dye in the solutions [44].

\subsection{Industrial Applicability}

This study indicates the effective interaction between phosphorylated xylan and a cationic dye. It is worth mentioning that the cationic dye was used only as a model of small molecules for the fundamental investigation in the current study. However, the practical application of phosphorylated xylan for dye removals may not be considered to be a stand-alone process since this process may generate phosphorylated xylan/dye sludges with a high water content that may be challenging to dispose of at industrial scales [12]. Therefore, a new separation process should be developed for the isolation of phosphorylated xylan/dye complexes to develop a phosphorylated xylan-based coagulation system for dye removal.

Simultaneous adsorption and flocculation have been reported to be effective in removing organic components from wastewater $[45,46]$. Phosphorylated xylan may be used along with other adsorbents for improving the efficiency of adsorbents in dye removal processes. The use of a coagulant in this case may help reduce the amounts of adsorbents used for dye removal, and a higher dye removal efficiency may be obtained if an adsorbent and a coagulant are used together. However, further studies are required to prove this concept, which was out of the scope of this study.

\section{Conclusions}

In this study, phosphorylated xylan with the maximum DS of 0.79 and charge density of $-3.40 \mathrm{mmol} / \mathrm{g}$ was produced under the optimal conditions of $80^{\circ} \mathrm{C}, 4 \mathrm{~h}$, and a xylan/STMP molar ratio of $1 / 3$. This product had a molecular weight $(M w)$ of $23,500 \mathrm{~g} / \mathrm{mol}$. FTIR, ascorbic acid analyses, and ICP-AES analyses confirmed that the phosphate groups were successfully grafted to the xylan backbone. The thermal stability of xylan was reduced through phosphorylation. The phosphorylated xylan was used as a flocculant, and the results confirmed that $96.5 \%$ of the dye and $93.6 \%$ of COD were removed from the dye solution $(100 \mathrm{mg} / \mathrm{L})$ with phosphorylated xylan at a concentration of $350 \mathrm{mg} / \mathrm{L}$. Furthermore, phosphorylated xylan was most effective in dye removal at $\mathrm{pH} 9$ and $30^{\circ} \mathrm{C}$. The experimental and theoretical analyses confirmed that the charge neutralization was the main interaction mechanism between the dye and phosphorylated xylan. The presence of salt slightly hampered the effectiveness of phosphorylated xylan in dye removal.

Acknowledgments: The authors are grateful to the National Natural Science Foundation of China (Grant Nos. 31570566, 31500489, 31600472), the Natural Science Foundation of Shandong (ZR2017LEM009), the Key Research and Development Program of Shandong Province (No. 2017GSF17130), the Foundation of Guangxi Key Laboratory of Clean Pulp \& Papermaking and Pollution Control of China (KF201717), and the Foundation of Key Laboratory of Pulp and Paper Science and Technology of Ministry of Education/Shandong Province of China (No. ZR201707, No. ZR201710). We would like to thank LetPub (www.letpub.com) for providing linguistic assistance during the preparation of this manuscript.

Author Contributions: Zhongming Liu, Dingding Xu, Fangong Kong, and Shoujuan Wang conceived and designed the experiments; Zhongming Liu and Dingding Xu performed the experiments; Zhongming Liu, Fangong Kong, and Shoujuan Wang analyzed the data; NanNan Xia, Xin Zhao, and GuihuaYang contributed 
reagents/materials/analysis tools; Pedram Fatehi measured the viscosity of samples and improved the language; Zhongming Liu, Fangong Kong, and Shoujuan Wang wrote the paper.

Conflicts of Interest: The authors declare no conflict of interest.

\section{References}

1. Hettrich, K.; Drechsler, U.; Loth, F.; Volkert, B. Preparation and characterization of water-soluble xylan ethers. Polymers 2017, 9, 129. [CrossRef]

2. Mao, J.; Abushammala, H.; Hettegger, H.; Rosenau, T.; Laborie, M.P.; Mao, J.; Abushammala, H.; Hettegger, H.; Rosenau, T.; Laborie, M.P. Imidazole, a new tunable reagent for producing nanocellulose, part I: Xylan-coated CNCs and CNFs. Polymers 2017, 9, 473. [CrossRef]

3. Bai, Y.-Y.; Xiao, L.-P.; Sun, R.-C. Microwave-assisted conversion of biomass derived hemicelluloses into xylo-oligosaccharides by novel sulfonated bamboo-based catalysts. Biomass Bioenergy 2015, 75, $245-253$. [CrossRef]

4. Daus, S.; Heinze, T. Xylan-based nanoparticles: Prodrugs for ibuprofen release. Macromol. Biosci. 2010, 10, 211-220. [CrossRef] [PubMed]

5. Wu, S.; Hu, J.; Wei, L.; Du, Y.; Shi, X.; Zhang, L. Antioxidant and antimicrobial activity of maillard reaction products from xylan with chitosan/chitooligomer/glucosamine hydrochloride/taurine model systems. Food Chem. 2014, 148, 196-203. [CrossRef] [PubMed]

6. Chaa, L.; Joly, N.; Lequart, V.; Faugeron, C.; Mollet, J.-C.; Martin, P.; Morvan, H. Isolation, characterization and valorization of hemicelluloses from aristida pungens leaves as biomaterial. Carbohydr. Polym. 2008, 74, 597-602. [CrossRef]

7. Willför, S.; Sundberg, K.; Tenkanen, M.; Holmbom, B. Spruce-derived mannans-A potential raw material for hydrocolloids and novel advanced natural materials. Carbohydr. Polym. 2008, 72, 197-210. [CrossRef]

8. Marcelino, H.R.; Silva, A.E.D.; Gomes, M.C.S.; Oliveira, E.E.; Nagashima-Junior, T.; Pinheiro, G.S.; Silva, A.E.; Timoteo, A.R.D.S.; Agnez-Lima, L.F.; Ayala, A.P.; et al. Leads from physical, chemical, and thermal characterization on cytotoxic effects of xylan-based microparticles. Polymers 2015, 7, 2304-2315. [CrossRef]

9. Wang, S.Y.; Li, H.L.; Ren, J.L.; Liu, C.F.; Peng, F.; Sun, R.C. Preparation of xylan citrate-A potential adsorbent for industrial wastewater treatment. Carbohydr. Polym. 2013, 92, 1960-1965.

10. Kong, F.; Wang, S.; Price, J.T.; Konduri, M.K.; Fatehi, P. Water soluble kraft lignin-acrylic acid copolymer: Synthesis and characterization. Green Chem. 2015, 17, 4355-4366. [CrossRef]

11. Chen, C.Y.; Yen, S.H.; Chung, Y.C. Combination of photoreactor and packed bed bioreactor for the removal of ethyl violet from wastewater. Chemosphere 2014, 117, 494-501. [CrossRef] [PubMed]

12. Lee, W.L.W.; Lu, C.S.; Lin, H.P.; Chen, J.Y.; Chen, C.C. Photocatalytic degradation of ethyl violet dye mediated by $\mathrm{TiO}_{2}$ under an anaerobic condition. J. Taiwan Inst. Chem. Eng. 2014, 45, 2469-2479. [CrossRef]

13. Wang, N.; Feng, Z.; Ma, X.; Zheng, P. The modification of rectorite with carbon layers and trisodium trimetaphosphate for the removal of $\mathrm{Pb}^{2+}$. Appl. Clay Sci. 2017, 146, 115-121. [CrossRef]

14. Igura, M.; Okazaki, M. Cadmium sorption characteristics of phosphorylated sago starch-extraction residue. J. Hazard. Mater. 2010, 178, 686-692. [CrossRef] [PubMed]

15. Dulong, V.; Lack, S.; Cerf, D.L.; Picton, L.; Vannier, J.P.; Muller, G. Hyaluronan-based hydrogels particles prepared by crosslinking with trisodium trimetaphosphate. Synthesis and characterization. Carbohydr. Polym. 2004, 57, 1-6. [CrossRef]

16. Zhang, M.; Su, N.; Zhang, Q.; Wang, Y.; Li, J.; Ye, M. Phosphorylation and antiaging activity of polysaccharide from trichosanthes peel. J. Food Drug Anal. 2017, 25, 976-983. [CrossRef] [PubMed]

17. Ming, K.; Chen, Y.; Yao, F.; Shi, J.; Yang, J.; Du, H.; Wang, X.; Wang, Y.; Liu, J. Phosphorylated codonopsis pilosula polysaccharide could inhibit the virulence of duck hepatitis a virus compared with codonopsis pilosula polysaccharide. Int. J. Biol. Macromol. 2017, 94, 28-35. [CrossRef] [PubMed]

18. Song, Y.; Ni, Y.; Hu, X.; Li, Q. Effect of phosphorylation on antioxidant activities of pumpkin (Cucurbita pepo, Lady godiva) polysaccharide. Int. J. Biol. Macromol. 2015, 81, 41-48. [CrossRef] [PubMed]

19. Ghimici, L.; Suflet, D.M. Phosphorylated polysaccharide derivatives as efficient separation agents for zinc and ferric oxides particles from water. Sep. Purif. Technol. 2015, 144, 31-36. [CrossRef] 
20. Ke, M.; Yun, C.; Shi, J.; Yang, J.; Yao, F.; Du, H.; Wei, Z.; Bai, J.; Liu, J.; Wang, D. Effects of chrysanthemum indicum polysaccharide and its phosphate on anti-duck hepatitis a virus and alleviating hepatic injury. Int. J. Biol. Macromol. 2017, 102, 813-821.

21. Rao, M.R.P.; Warrier, D.U.; Gaikwad, S.R.; Shevate, P.M. Phosphorylation of psyllium seed polysaccharide and its characterization. Int. J. Biol. Macromol. 2016, 85, 317-326. [CrossRef] [PubMed]

22. Woggum, T.; Sirivongpaisal, P.; Wittaya, T. Properties and characteristics of dual-modified rice starch based biodegradable films. Int. J. Biol. Macromol. 2014, 67, 490-502. [CrossRef] [PubMed]

23. Dulong, V.; Forbice, R.; Condamine, E.; Cerf, D.L.; Picton, L. Pullulan-stmp hydrogels: A way to correlate crosslinking mechanism, structure and physicochemical properties. Polym. Bull. 2011, 67, 455-466. [CrossRef]

24. Konduri, M.K.; Fatehi, P. Synthesis and characterization of carboxymethylated xylan and its application as a dispersant. Carbohydr. Polym. 2016, 146, 26-35. [CrossRef] [PubMed]

25. Deng, C.; Fu, H.; Xu, J.; Shang, J.; Cheng, Y. Physiochemical and biological properties of phosphorylated polysaccharides from dictyophora indusiata. Int. J. Biol. Macromol. 2015, 72, 894-899. [CrossRef] [PubMed]

26. Bhumkar, D.R.; Pokharkar, V.B. Studies on effect of ph on cross-linking of chitosan with sodium tripolyphosphate: A technical note. Aaps Pharmscitech 2006, 7, E138-E143. [CrossRef] [PubMed]

27. He, W.; Zhang, Y.; Fatehi, P. Sulfomethylated kraft lignin as a flocculant for cationic dye. Colloids Surf. A Physicochem. Eng. Asp. 2016, 503, 19-27. [CrossRef]

28. Soyeon, J.; Jaewon, L. Optimization of pretreatment condition for ethanol production from oxalic acid pretreated biomass by response surface methodology. Ind. Crops Prod. 2016, 79, 1-6.

29. Wei, D.; Cheng, W.; Wei, Y.; Zhang, L. Phosphorylated modification and in vitro antioxidant activity of radix hedysari polysaccharide. Glycoconj. J. 2012, 29, 167-172. [CrossRef] [PubMed]

30. Ren, J.; Peng, F.; Sun, R.; Liu, C.; Cao, Z.; Luo, W.; Tang, J. Synthesis of cationic hemicellulosic derivatives with a low degree of substitution in dimethyl sulfoxide media. J. Appl. Polym. Sci. 2008, 109, 2711-2717. [CrossRef]

31. Kurita, O.; Fujiwara, T.; Yamazaki, E. Characterization of the pectin extracted from citrus peel in the presence of citric acid. Carbohydr. Polym. 2008, 74, 725-730. [CrossRef]

32. Hansen, N.M.; Plackett, D. Synthesis and characterization of birch wood xylan succinoylated in 1-n-butyl-3-methylimidazolium chloride. Polym. Chem. 2011, 2, 2010-2020. [CrossRef]

33. Peng, P.; Zhai, M.; She, D.; Gao, Y. Synthesis and characterization of carboxymethyl xylan-g-poly(propylene oxide) and its application in films. Carbohydr. Polym. 2015, 133, 117-125. [CrossRef] [PubMed]

34. Zhang, X.; Liu, C.; Zhang, A.; Sun, R.; Zhang, X.; Liu, C.; Zhang, A.; Sun, R.; Zhang, X.; Liu, C. Organic catalysis for ring-opening graft polymerization of $p$-dioxanone with xylan in ionic liquid. Polymers 2017, 9, 345. [CrossRef]

35. Peng, X.-W.; Ren, J.-L.; Zhong, L.-X.; Peng, F.; Sun, R.-C. Xylan-rich hemicelluloses-graft-acrylic acid ionic hydrogels with rapid responses to PH, salt, and organic solvents. J. Agric. Food Chem. 2011, 59, 8208-8215. [CrossRef] [PubMed]

36. Xie, W.; Shao, L. Phosphorylation of corn starch in an ionic liquid. Starch Stärke 2009, 61, 702-708. [CrossRef]

37. $\mathrm{CH}$, Ü.; Kutlu, M.; Atıc1, O.G. Mannich reaction of polysaccharides: Xylan functionalization in aqueous basic medium. Carbohydr. Polym. 2015, 127, 19-27.

38. Xin, X.; Xu, G.; Gong, H.; Bai, Y.; Tan, Y. Interaction between sodium oleate and partially hydrolyzed polyacrylamide: A rheological study. Colloids Surf. A Physicochem. Eng. Asp. 2008, 326, 1-9. [CrossRef]

39. Patruyo, L.; Müller, A.; Saez, A. Shear and extensional rheology of solutions of modified hydroxyethyl celluloses and sodium dodecyl sulfate. Polymer 2002, 43, 6481-6493. [CrossRef]

40. Fang, R.; Cheng, X.S.; Xu, X.R. Synthesis of lignin-base cationic flocculant and its application in removing anionic azo-dyes from simulated wastewater. Bioresour. Technol. 2010, 101, 7323-7329. [CrossRef] [PubMed]

41. Mishra, A.; Bajpai, M. The flocculation performance of tamarindus mucilage in relation to removal of vat and direct dyes. Bioresour. Technol. 2006, 97, 1055-1059. [CrossRef] [PubMed]

42. Guibal, E.; Roussy, J. Coagulation and flocculation of dye-containing solutions using a biopolymer (chitosan). React. Funct. Polym. 2007, 67, 33-42. [CrossRef]

43. Yang, Z.; Yang, H.; Jiang, Z.; Cai, T.; Li, H.; Li, H.; Li, A.; Cheng, R. Flocculation of both anionic and cationic dyes in aqueous solutions by the amphoteric grafting flocculant carboxymethyl chitosan-graft-polyacrylamide. J. Hazard. Mater. 2013, 255, 36-45. [CrossRef] [PubMed] 
44. Mishra, A.; Bajpai, M. Flocculation behaviour of model textile wastewater treated with a food grade polysaccharide. J. Hazard. Mater. 2005, 118, 213-217. [CrossRef] [PubMed]

45. Liu, X.; Fatehi, P.; Ni, Y. Adsorption of lignocelluloses dissolved in prehydrolysis liquor of kraft-based dissolving pulp process on oxidized activated carbons. Ind. Eng. Chem. Res. 2011, 50, 11706-11711. [CrossRef]

46. Liu, X.; Fatehi, P.; Ni, Y. Removal of inhibitors from pre-hydrolysis liquor of kraft-based dissolving pulp production process using adsorption and flocculation processes. Bioresour. Technol. 2012, 116, 492-496. [CrossRef] [PubMed]

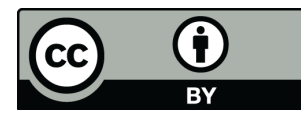

(c) 2018 by the authors. Licensee MDPI, Basel, Switzerland. This article is an open access article distributed under the terms and conditions of the Creative Commons Attribution (CC BY) license (http://creativecommons.org/licenses/by/4.0/). 